\title{
EQUIPAMENTO MICROPROCESSADO PARA GERAÇÃO DE SINAL DE CORREÇÃO DIFERENCIAL, EM TEMPO REAL, PARA GPS ${ }^{1}$
}

\author{
THALES C. B. LIMA ${ }^{2}$, CLAUDIO K. UMEZU ${ }^{3}$, NELSON L. CAPPELLI ${ }^{4}$, \\ EDUARDO F. NUNES ${ }^{5}$
}

\begin{abstract}
RESUMO: Este trabalho apresenta o desenvolvimento de um equipamento microprocessado, de baixo custo, para geração de sinal de correção diferencial para GPS, em tempo real, e configuração e supervisão do receptor GPS base. O equipamento desenvolvido possui um microcontrolador dedicado, display alfanumérico, teclado multifunção para configuração e operação do sistema e interfaces de comunicação. $\mathrm{O}$ circuito eletrônico do equipamento tem a função de receber as informações do GPS base e interpretá-las, transformando-as numa sentença no protocolo RTCM SC-104. O software do microcontrolador é responsável pela conversão do sinal recebido pelo GPS base, do formato proprietário para o protocolo RTCM SC-104. A placa processadora principal possui duas interfaces seriais padrão RS-232C. Uma delas tem a função de configuração e leitura das informações geradas pelo receptor GPS base. A outra atua somente como saída, enviando o sinal de correção diferencial. O projeto do equipamento microprocessado mostrou que é possível a construção de uma estação privada para a geração do sinal de correção diferencial, de baixo custo.
\end{abstract}

PALAVRAS-CHAVE: DGPS, RTCM SC-104, microprocessador.

\section{MICROPROCESSOR-BASED EQUIPMENT FOR REAL TIME GENERATION OF DIFFERENTIAL GPS CORRECTION SIGNAL}

\begin{abstract}
This work presents the development of low cost microprocessor-based equipment for generation of differential GPS correction signal, in real time, and configuration and supervision of the GPS base. The developed equipment contains a dedicated microcontroller connected to the GPS receiver, alphanumeric display and multifunction keyboard for configuration and operation of the system and communication interfaces. The electronic circuit has the function of receiving the information from GPS base; interpret them, converting the sentence in the RTCM SC-104 protocol. The microcontroller software makes the conversion of the signal received by the GPS base from the specific format to RTCM SC-104 protocol. The processing main board has two serials RS232C standard interfaces. One of them is used for configuration and receiving the information generated by the GPS base. The other operates as output, sending the differential correction signal for the transmission system. The development of microprocessor-based equipment showed that it is possible the construction of a low cost private station for real time generation of differential GPS correction signal.
\end{abstract}

KEYWORDS: DGPS, RTCM SC-104, microprocessor.

\section{INTRODUÇÃO}

O Sistema de Posicionamento Global (NAVSTAR GPS) é, na atualidade, o sistema de posicionamento global mais difundido e utilizado. Foi desenvolvido pelo Departamento de Defesa dos EUA e, inicialmente, concebido para uso militar. A partir de meados da década de 1970, o seu uso foi estendido para aplicações civis, tendo passado por contínua evolução tanto nos aspectos de

\footnotetext{
${ }^{1}$ Extraído da tese de doutorado do primeiro autor. Projeto financiado pela FAPESP.

${ }^{2}$ Eng $^{\mathrm{o}}$ de Computação, Doutorando em Engenharia Agrícola, Laboratório de Instrumentação e Controle - LIC, FEAGRI/UNICAMP, Campinas - SP.

${ }^{3}$ Eng ${ }^{\mathrm{o}}$ Eletricista, Pesquisador, LIC, FEAGRI/UNICAMP, Campinas - SP, umezu @ agr.unicamp.br

${ }^{4}$ Eng $^{\mathrm{O}}$ Agrícola, Prof. Doutor, LIC, FEAGRI/UNICAMP, Campinas - SP.

${ }^{5}$ Eng $^{\mathrm{o}}$ Eletricista, LIC, FEAGRI/UNICAMP, Campinas - SP.

Recebido pelo Conselho Editorial em: 31-8-2004
}

Aprovado pelo Conselho Editorial em: 9-8-2006 
hardware quanto de programas computacionais. O princípio básico de funcionamento da tecnologia do GPS está na trilateração, utilizando os satélites como pontos de referência precisos, onde a localização é previamente conhecida. O GPS determina a posição, medindo a distância entre o aparelho receptor e os satélites no espaço. Cada satélite emite, de forma contínua, informações de sua posição e um sinal de tempo para sincronismo. O receptor determina o tempo que o sinal leva para percorrer a distância entre o satélite e o receptor. Conhecendo as coordenadas do satélite em um sistema de referência adequado, podem-se determinar as coordenadas do usuário (Figura 1). Uma das técnicas mais empregadas para o cálculo da posição no sistema GPS é a pseudodistância, obtida a partir dos códigos gerados pelos satélites da constelação do GPS.

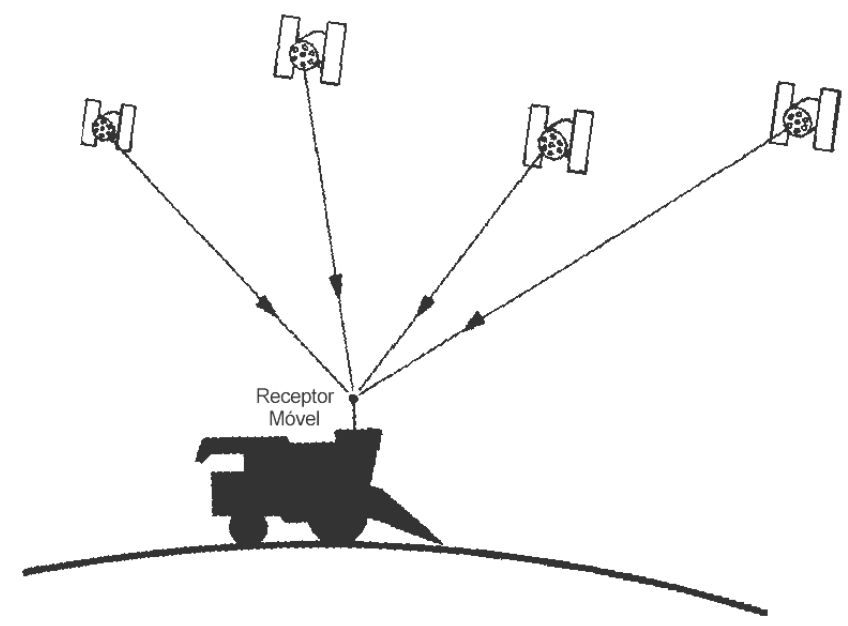

FIGURA 1. Funcionamento do GPS (adaptada de MORGAN \& ESS, 1997).

MARQUES (2000) comenta que, nas medidas de pseudodistâncias, encontram-se diversos tipos de erros, a saber: erros dos relógios dos satélites, erros dos relógios dos receptores, erros das efemérides (órbitas dos satélites), atraso ionosférico, atraso troposférico, multicaminhamento, erros relativísticos, condições relativas à geometria dos satélites (DOP), erros na recepção do sinal e erros referentes a ruídos no receptor. Esses erros na medição do posicionamento, dependendo do tipo da aplicação, podem interferir significativamente nos resultados esperados. O acesso ao sistema GPS se dá de forma ininterrupta, em todo o planeta, independentemente das condições meteorológicas (embora essas interfiram de certa forma na precisão das medidas).

Para obter maior precisão do GPS, pode ser utilizada a técnica de correção diferencial, sendo esse sistema conhecido como Sistema de Posicionamento Global Diferencial (DGPS) ou GPS diferencial. O DGPS permite obter menor erro na determinação do posicionamento, sendo uma técnica empregada para remover a maioria dos erros aleatórios na utilização do GPS. O funcionamento do mesmo baseia-se na hipótese de que o erro na determinação de um ponto é semelhante para todos os receptores situados em um raio de até centenas de quilômetros. A eliminação desse erro permite que o usuário reduza significativamente o erro total presente.

Nesse sistema, faz-se uso de um segundo receptor GPS, geralmente denominado de estaçãobase ou de referência, fixado em um ponto de coordenadas conhecidas, que pode operar simultaneamente com vários receptores GPS móveis. Os GPS móveis são utilizados na determinação das coordenadas do usuário, permitindo, assim, calcular a diferença entre a posição obtida por meio desse receptor GPS base e a posição real. Segundo GORGULHO (2001), o DGPS é um processo que permite ao usuário civil obter precisão de 20 milímetros a 5 metros, pelo processamento contínuo de correções nos sinais, dependendo da qualidade do receptor e do sinal de correção utilizados.

Para que a correção diferencial possa ser realizada, algumas condições devem ser preenchidas:

- A estação-base não deve estar muito distante da área de operação do receptor móvel, de modo que a constelação de satélites seja a mesma para os dois receptores. Os sinais de correção são 
válidos para uma distância de até $400 \mathrm{~km}$ da estação-base. Porém, para que a precisão máxima seja obtida, a distância entre ambos deve ser de até $50 \mathrm{~km}$;

- A estação-base deve estar localizada em um ponto de coordenada cartográfica precisamente conhecida, e

- Os dados gerados pela estação-base e pela estação móvel devem ser compatíveis e ocorrerem simultaneamente.

A correção diferencial pode ser realizada de duas formas: pós-processada ou em tempo real. Nessa última, o sinal de correção é enviado em tempo real ao receptor móvel para realizar as devidas correções no sinal recebido. As fontes mais utilizadas de geração do sinal de correção diferencial são os rádios-faróis operados pela marinha, estações de rádio terrestres ou ainda satélites de comunicação. Uma alternativa para a geração do sinal de correção diferencial é a utilização de uma estação de correção privada (Figura 2), tendo em vista que outras fontes de geração do sinal de correção podem ser inviáveis por questões geográficas, econômicas e políticas.

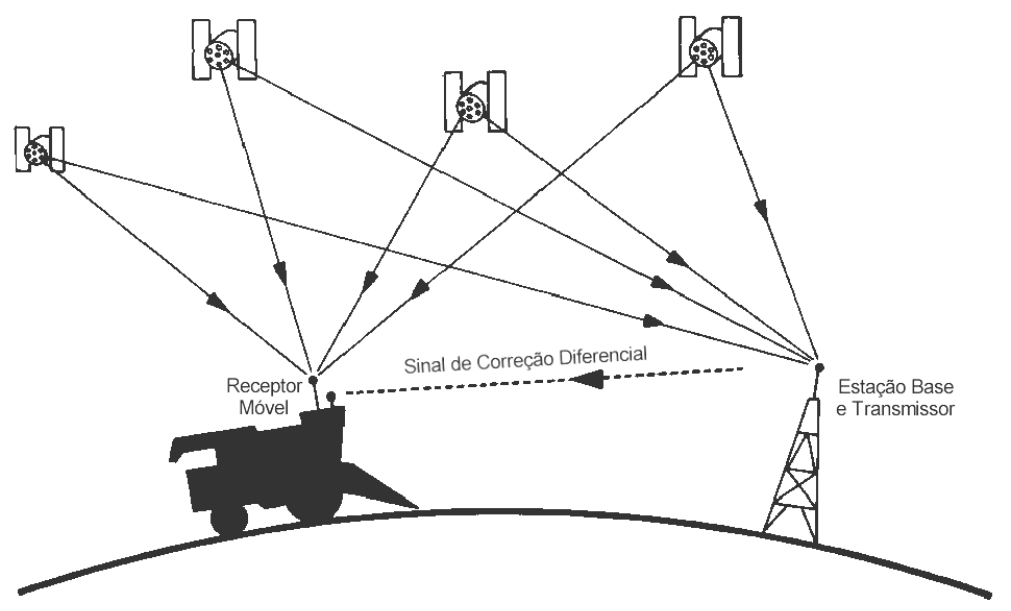

FIGURA 2. Conceito da correção diferencial em tempo real (adaptada de MORGAN \& ESS, 1997).

Segundo MONICO (2000), o DGPS foi desenvolvido com o objetivo de minimizar os efeitos da disponibilidade seletiva (S/A) imposta ao GPS no modo absoluto, conhecido como SPS (Standard Positioning Service). Segundo o autor, sua utilização original foi na navegação, mas atualmente é empregada em diversas atividades, inclusive na agricultura.

O protocolo de comunicação mais utilizado para a transmissão de sinais de correção diferencial em tempo real para os sistemas de GPS é o RTCM SC-104 (Radio Technical Commission for Maritime Services). Para a utilização do DGPS, é necessário que o receptor GPS seja compatível com tal tecnologia e permita o recebimento do sinal de correção através do meio de transmissão escolhido.

A motivação para o desenvolvimento deste trabalho partiu da constatação da limitada disponibilidade de equipamentos e informações para a montagem de uma base privada para correção diferencial, em tempo real, de sinais GPS. Isso cria obstáculos de ordem técnica, geralmente na compatibilidade entre os equipamentos e na adequação às necessidades do usuário. Porém, o maior obstáculo, sem dúvida nenhuma, é o elevado custo dos equipamentos e de sua instalação e que, certamente, inviabiliza o uso de tal tecnologia para a maioria das aplicações.

Nesse sentido, UMEZU \& CAPPELLI (2002) iniciaram o desenvolvimento de uma estaçãobase de correção diferencial, de baixo custo, para a geração do sinal de correção diferencial para GPS. LIMA et al. (2003) e UMEZU et al. (2004) propuseram metodologia para a geração do sinal de correção no protocolo RTCM SC-104. 
Este trabalho apresenta o desenvolvimento de um equipamento microprocessado, de baixo custo, para geração de sinal de correção diferencial para GPS, em tempo real, bem como para a configuração e a supervisão do receptor GPS base.

\section{MATERIAL E MÉTODOS}

\section{Arquitetura do equipamento}

Do ponto de vista físico, o equipamento de correção diferencial desenvolvido pode ser subdividido em duas partes: a estação-base de correção - parte fixa do sistema que deve ser instalada em um local georreferenciado, protegida e com disponibilidade de alimentação elétrica, e um módulo receptor móvel que deve estar acoplado a cada um dos receptores GPS utilizados para a coleta de posições georreferenciadas (Figura 3).

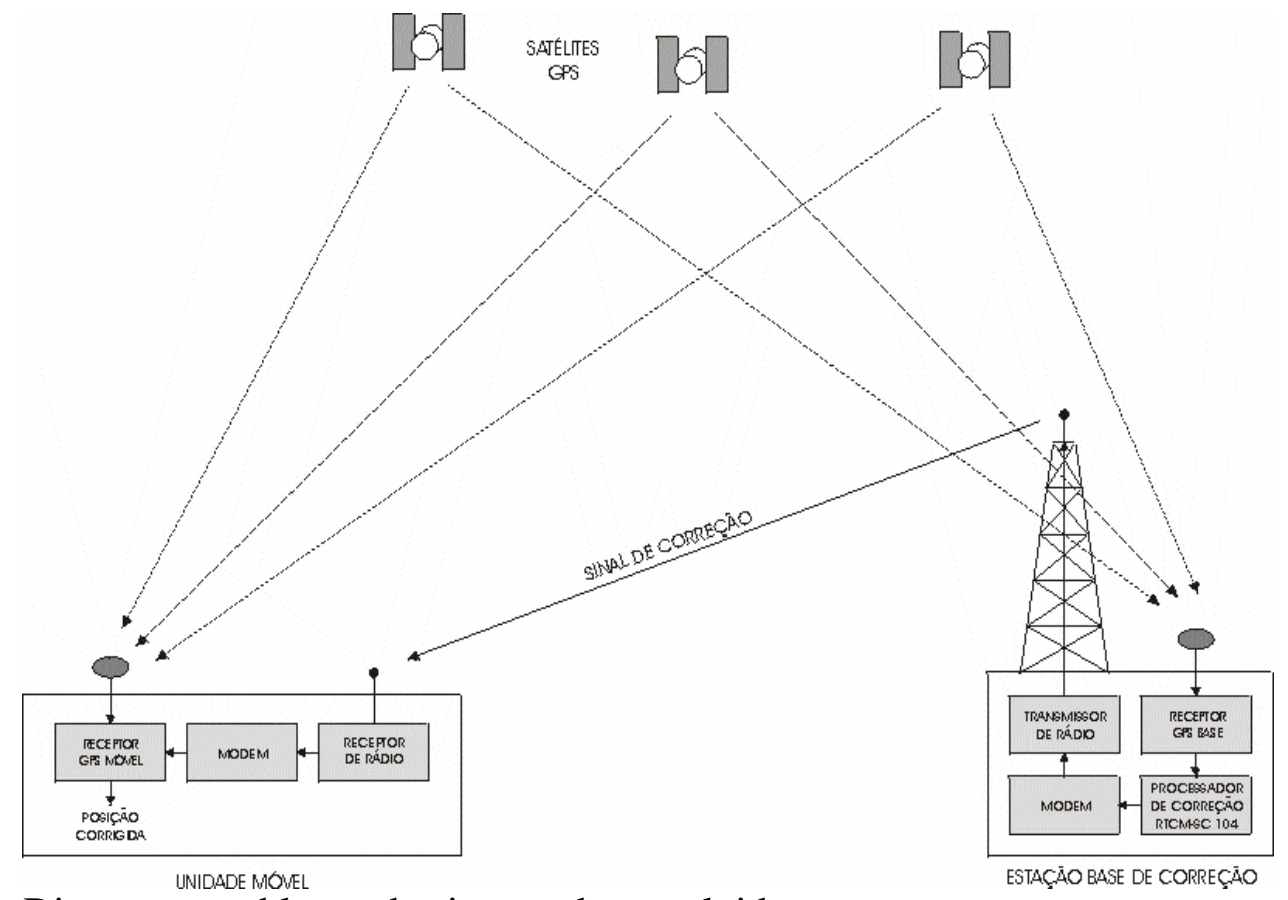

FIGURA 3. Diagrama em blocos do sistema desenvolvido.

\section{Estação-base}

A estação-base é constituída por quatro subsistemas: 1) receptor GPS base; 2) sistema de processamento para configuração do GPS e geração da mensagem de correção; 3) conversor de taxa e modulador, e 4) sistema de transmissão por rádio. Na Figura 4, apresenta-se o diagrama de blocos simplificado, com os principais componentes da estação de correção diferencial.

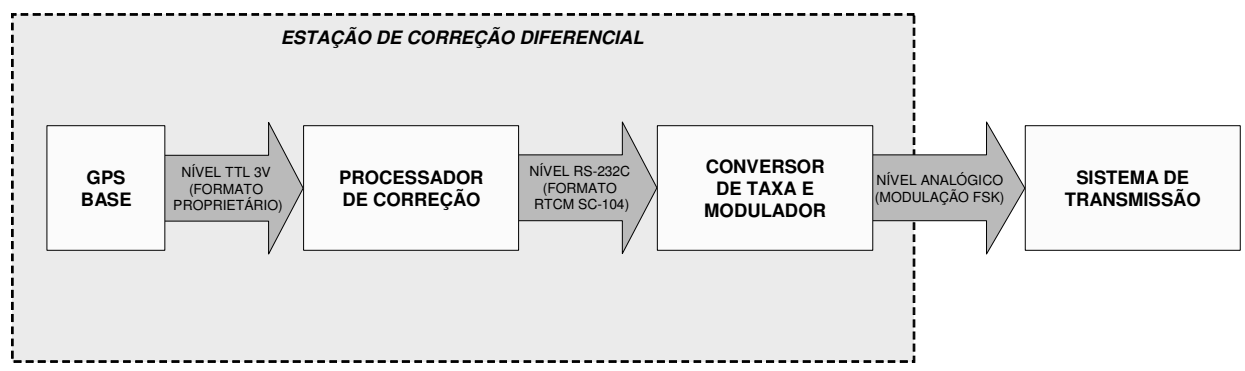

FIGURA 4. Diagrama de blocos com os principais componentes da estação de correção diferencial.

O sistema de transmissão, apesar de ser parte essencial no funcionamento da estação de correção diferencial, não é considerado como parte da mesma, visto que, dependendo das necessidades de cada utilização, poderá ser composto por diferentes soluções para a transmissão dos dados. 
O equipamento desenvolvido tem como função básica gerar o sinal de correção diferencial no formato RTCM SC-104, a partir do sinal de correção enviado por um receptor GPS base no formato proprietário. Também é responsável pela configuração de parâmetros operacionais do receptor GPS, tais como: coordenadas, altitude, taxa de atualização, etc. Utilizou-se como GPS base uma placa receptora da marca Motorola, modelo M12+ Oncore, com 12 canais paralelos, interface serial TTL, alimentação de 2,75 a 3,3 Vdc, consumo de corrente de $16 \mathrm{~mA}$, peso de $25 \mathrm{~g}$, dimensões 40 × 60 × $10 \mathrm{~mm}$ ( $\mathrm{L}$ × P x A), entrada para antena ativa, entrada para sinal de correção, suporte da operação como estação-base e custo aproximado de US\$ 75,00 (Figura 5).

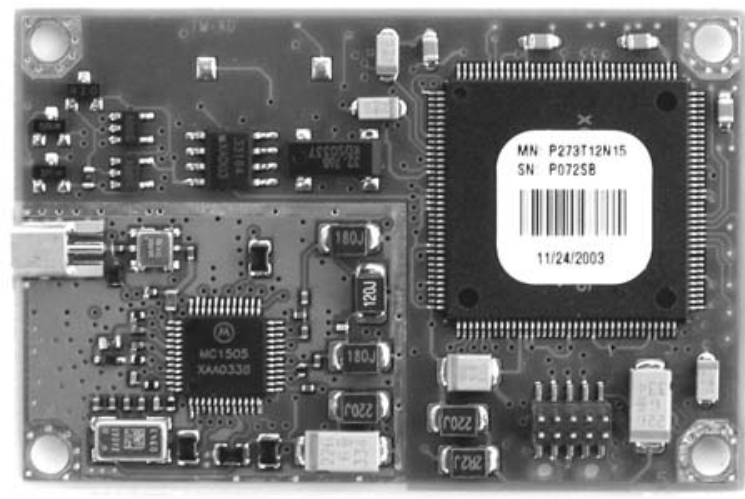

FIGURA 5. Placa receptora GPS Motorola, modelo M12+ Oncore.

O equipamento de correção possui como principal componente o microcontrolador MSP430F149, da família MSP-430, fabricado pela Texas Instruments. O MSP430 possui arquitetura RISC (Reduced Instruction Set Computer) e processamento em 16 bits, tendo como principais características: conversor $\mathrm{A} / \mathrm{D}$ com resolução 12 bits, oito entradas analógicas, memória Flash com $60 \mathrm{kB}$, memória RAM com $2 \mathrm{kB}$, duas portas seriais, 48 pinos de entrada e saída, tensão de alimentação de 1,8 a 3,6 Vdc, programação on board (sem a necessidade da remoção do componente), tamanho físico reduzido (aproximadamente $10 \times 10 \mathrm{~mm}$ ) e custo aproximado de US\$ 10,00 .

Foi utilizado um display alfanumérico, marca Powertip, modelo PC 1602-F, de duas linhas e 16 colunas, para possibilitar a configuração do processador de correção e também do receptor GPS base. Por meio do display, é possível visualizar informações referentes ao funcionamento do sistema de geração de sinal para correção diferencial. Um teclado alfanumérico de 18 teclas, especialmente desenvolvido, foi incorporado ao equipamento para a configuração do GPS, acesso aos menus de configuração do equipamento, etc.

A partir dos requisitos técnicos do equipamento, foi projetado um circuito eletrônico, fundamentado no microcontrolador MSP430, incorporando as interfaces de entrada e saída, memória Flash serial (M25P10 - $1 \mathrm{Mb}$ ) e interfaces seriais de comunicação. O circuito eletrônico foi montado em uma placa de circuito impresso, dupla face, com tecnologia SMD (Surface Mounted Device), o que permitiu significativa redução do tamanho da placa. Na Figura 6, mostrase o diagrama de blocos do equipamento desenvolvido, com seus principais componentes e conexões.

A interface com o display de cristal líquido utilizou oito pinos do microcontrolador, configurados como saídas, enviando informações codificadas segundo a tabela ASCII. Para a implementação do teclado, foram utilizados nove pinos de entrada/saída do microcontrolador.

O circuito integrado MAX 232 foi utilizado para a conversão dos sinais seriais de níveis de tensão do padrão TTL-3V para níveis de tensão segundo o padrão RS-232C, e vice-versa. Com a finalidade de fornecer 3,3 Vdc para a alimentação do microcontrolador e do GPS base, foi incorporado na placa do equipamento um regulador de tensão modelo TPS76933. 


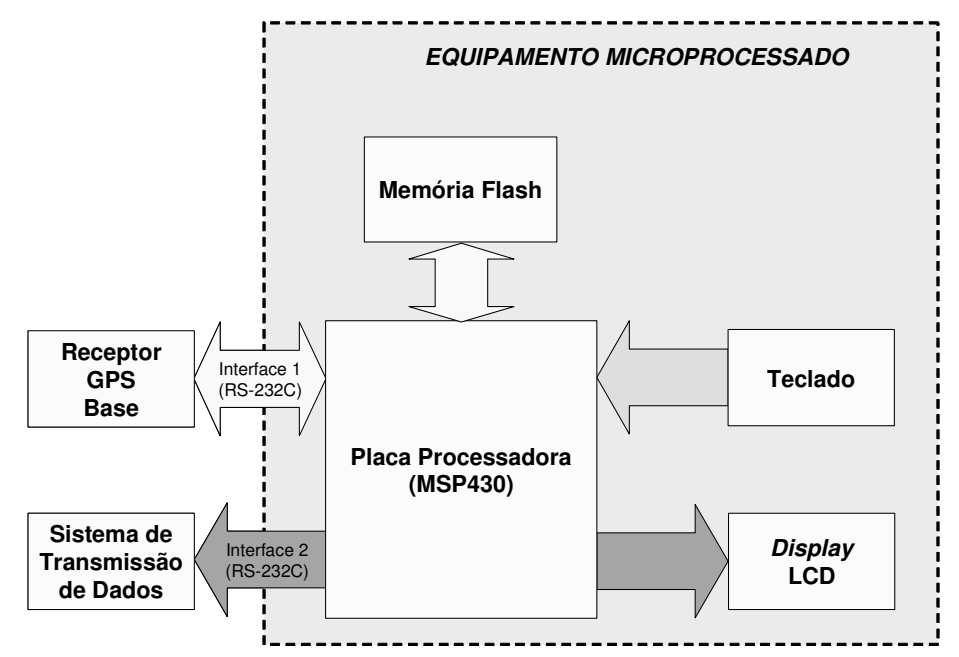

FIGURA 6. Diagrama de blocos do equipamento microprocessado, mostrando os principais componentes e conexões.

\section{Módulo Receptor Móvel}

A unidade móvel do sistema de correção diferencial é composta pelos seguintes equipamentos: sistema de recepção, módulo receptor e equipamento GPS (Figura 7). O módulo receptor tem a função de demodular o sinal de correção e convertê-lo para taxa de transmissão adequada ao GPS móvel utilizado. Para cada GPS móvel, utilizado simultaneamente, será necessária a utilização de um sistema de recepção e um módulo receptor. A exemplo do sistema de transmissão, o sistema de recepção não é considerado como parte integrante do sistema de correção diferencial, visto que diversas soluções poderão ser empregadas para o recebimento do sinal de correção.

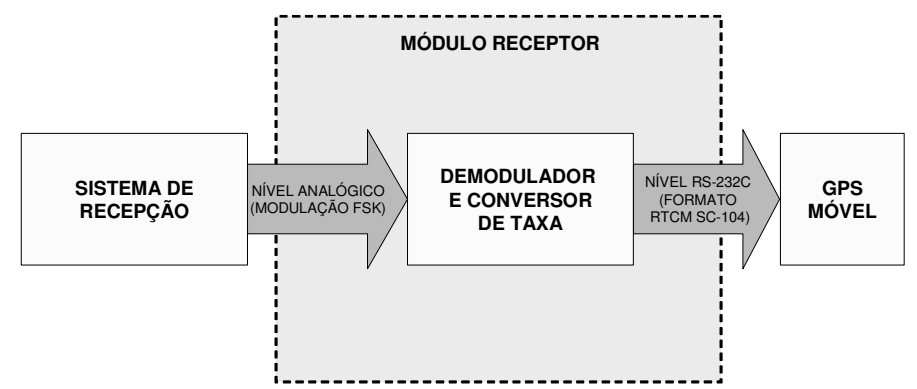

FIGURA 7. Diagrama de blocos do módulo receptor da estação de correção diferencial.

\section{Aplicativos computacionais}

Para a configuração do equipamento, controle do GPS e operação no modo de georreferenciamento, foi inicialmente desenvolvido um aplicativo computacional, utilizando-se do ambiente $\mathrm{C}^{++}$Builder, versão 5.0, desenvolvido pela Borland, para plataforma PC. Embora a ferramenta utilizada dispusesse de uma série de recursos para facilitar o desenvolvimento do software, procurou-se utilizar somente os recursos-padrão da linguagem ANSI C, facilitando o processo de conversão para o ambiente $\mathrm{C} / \mathrm{C}^{++}$específico do microcontrolador. Após testes e validação desses aplicativos, os mesmos foram adaptados e compilados para execução no microcontrolador MSP 430, utilizando-se do ambiente de programação EW-430, fabricado pela IAR Systems. Não foi necessário efetuar alterações significativas no programa-fonte em virtude de mudança da plataforma do hardware, sendo muitas vezes suficiente apenas recompilar o programafonte para a nova plataforma.

Para a construção das sentenças RTCM SC-104, desenvolveu-se um aplicativo que monta as palavras de 30 bits e calcula a paridade de cada uma das palavras. O software desenvolvido consiste de cinco rotinas principais: inicialização das portas seriais; leitura das sentenças do GPS 
base; conversão e processamento dos campos de informação do formato proprietário da Motorola em codificação binária para o padrão RTCM SC-104; montagem das sentenças RTCM e, por fim, escrita da mensagem de correção na porta serial adequada.

\section{RESULTADOS E DISCUSSÃO}

\section{Circuitos eletrônicos}

O estabelecimento de um nível de 3,3 Vdc para a alimentação do microcontrolador e do GPS permitiu que o equipamento operasse com uma ampla faixa de tensões de alimentação, tipicamente de 12 a $24 \mathrm{Vdc}$, fato que, aliado ao baixo consumo, facilitou sua utilização nas diferentes situações de campo. A conversão dos sinais seriais do padrão TTL para o padrão RS-232C, permite a conexão do equipamento diretamente a outros sistemas de transmissão, como, por exemplo, os rádios-modem comerciais. Na Figura 8, mostra-se o diagrama funcional do equipamento microprocessado.

O módulo receptor possui como principais componentes o microcontrolador PIC 16F876, fabricado pela Microchip, e o modem FSK MX 614. Na Figura 9, ilustra-se o diagrama funcional do módulo receptor.

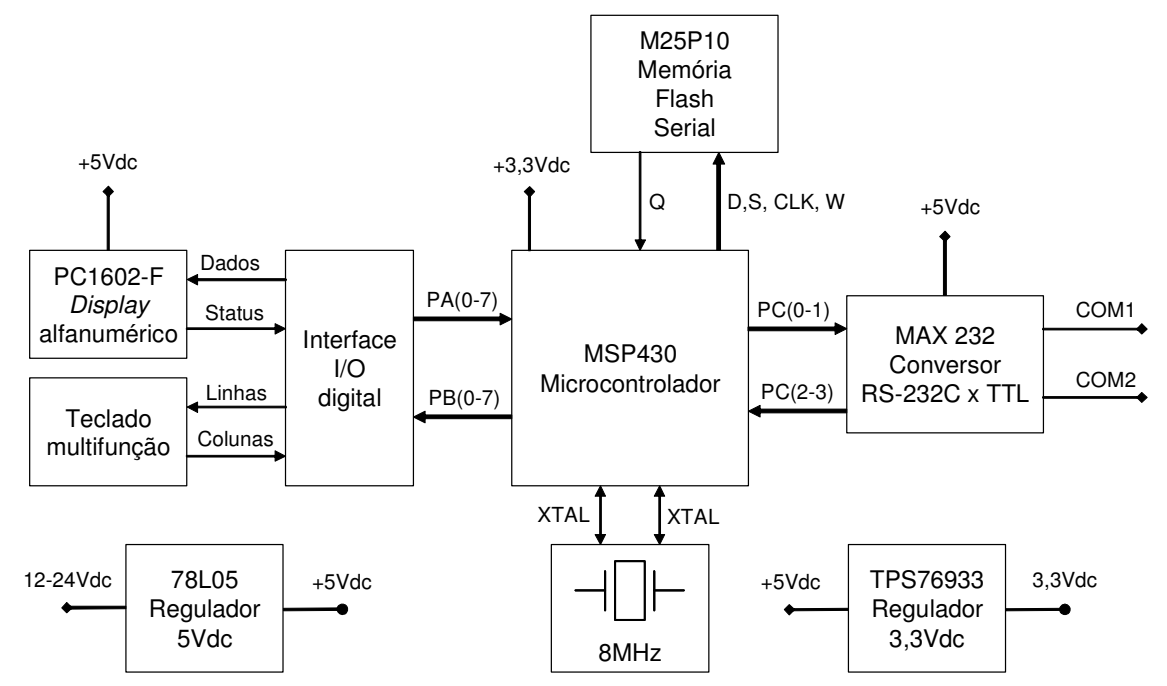

FIGURA 8. Diagrama funcional do equipamento microprocessado para geração do sinal de correção diferencial.

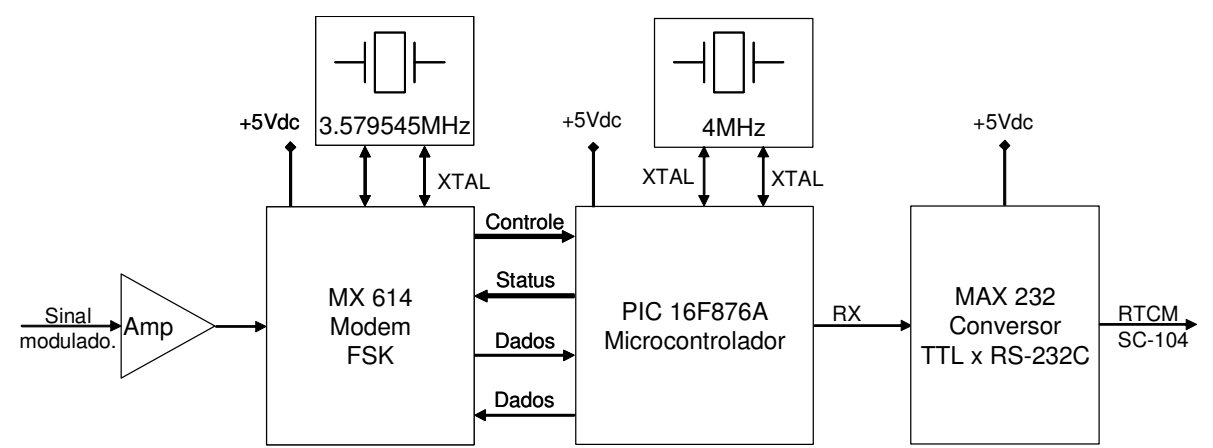

FIGURA 9. Diagrama funcional do módulo receptor da estação de correção diferencial.

\section{Placas eletrônicas}

Na Figura 10, mostra-se a placa eletrônica principal e a placa de interface de operação e configuração, especialmente fabricadas para o equipamento, vistas pelo lado dos componentes. A interface de operação e configuração foi elaborada utilizando uma única placa de circuito impresso, 
dupla face, onde foram montadas as chaves que constituem o teclado e também o display alfanumérico de cristal líquido.

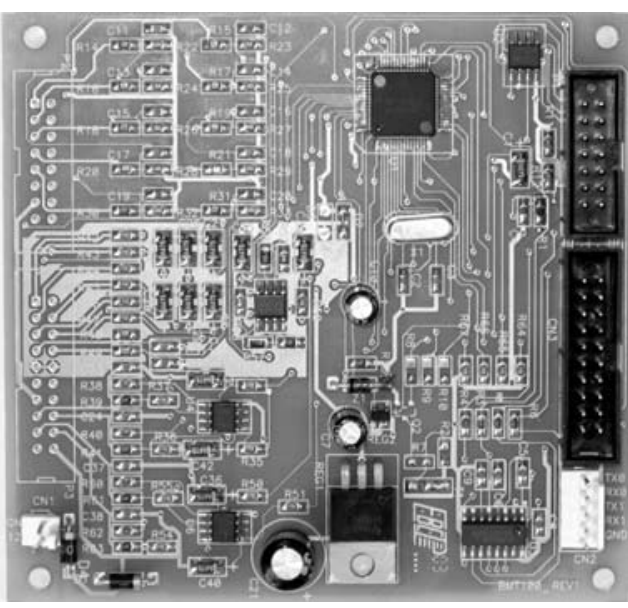

a)

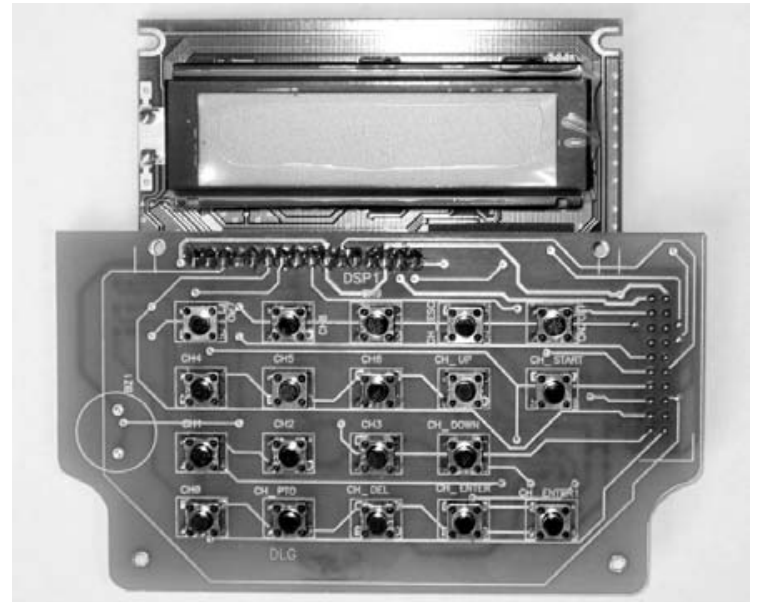

b)

FIGURA 10. a) Placa eletrônica do equipamento vista pelo lado dos componentes. Na parte superior, observa-se o microcontrolador e à direita os conectores do teclado/display e de programação. b) Placa da interface de operação e configuração. Na parte superior, encontra-se o display de cristal líquido e na parte inferior o teclado multifunção.

\section{Modos de operação}

O equipamento desenvolvido possui três modos de operação distintos:

Modo 1 - Configuração: possibilita a configuração do GPS base, permitindo ao usuário inserir ou modificar os dados de posição (latitude, longitude e altitude) da estação-base, selecionar a taxa de envio de dados de correção (1; 2; 5 ou 10 segundos de intervalo entre os dados) e, ainda, verificar características funcionais (tensão da bateria, senha de segurança, etc.). Nesse modo, o equipamento utiliza a interface COM1, no modo bidirecional, para realizar a comunicação com o receptor-base, à velocidade de 9600 bps, ficando inoperante a interface COM2.

Modo 2 - Operação DGPS: o equipamento recebe as informações de correção do GPS base, no formato proprietário, à taxa de 9600 bps, transformando-as para o formato RTCM SC-104. A seguir, o microprocessador realiza, se necessário, alteração na velocidade de transmissão (para 4800; 2400 ou 1200 bps), visando à compatibilidade com o sistema de modulação e transmissão utilizado. A interface COM1 opera em modo unidirecional, como entrada, e a interface COM2, também em modo unidirecional, como saída.

Modo 3 - Georreferenciamento: este modo é utilizado para o georreferenciamento da antena da estação-base. O GPS base opera no modo de navegação, enviando informações de posicionamento para o equipamento microprocessado e efetua cálculos estatísticos para fornecer estimativa das coordenadas e da altitude da antena. Neste modo, a interface COM1 opera como entrada unidirecional à velocidade de 9600 bps.

\section{CONCLUSÕES}

É possível a construção de uma estação privada para a geração do sinal de correção diferencial, de baixo custo, baseada em um sistema microprocessado. Uma das principais características do equipamento desenvolvido, diz respeito à sua forma de utilização, pois atua de forma autônoma, não dependendo de nenhum equipamento externo para o seu correto funcionamento.

Diversas atividades que hoje utilizam localização por GPS, com pós-processamento do sinal para aumento da precisão, podem fazer uso do sistema proposto, tendo como principal vantagem a 
utilização de receptores GPS de menor custo e a supressão da estação de coleta de dados para pósprocessamento, além da possibilidade de trabalhar em tempo real.

O custo final do protótipo desenvolvido foi de aproximadamente US\$1.000,00. Pretende-se, devido ao baixo custo e versatilidade do sistema de correção diferencial desenvolvido, ampliar significativamente o potencial de utilização de sistemas de posicionamento ao meio agrícola, em virtude dos benefícios técnicos e econômicos apresentados.

\section{AGRADECIMENTOS}

À DLG Automação Industrial Ltda., pelo auxílio técnico, à Fundação de Amparo à Pesquisa do Estado de São Paulo - FAPESP, pelo apoio financeiro, e ao Laboratório de Instrumentação e Controle da FEAGRI - UNICAMP, pela cessão de sua infra-estrutura.

\section{REFERENCIAS}

GORGULHO, M. Apostila de GPS - O Sistema de Posicionamento Global. GPS TrackMaker. 2001. Disponível em: <http://gpstm.com/port/apostila_port.htm>. Acesso em: 10 out. 2005.

LIMA, T.C.B.; CAPPELLI, N.L.; UMEZU, C.K.; NUNES, E.F. Sistema de geração de sinais de correção diferencial para GPS. In: CONGRESSO BRASILEIRO DA SOCIEDADE BRASILEIRA DE INFORMÁTICA APLICADA À AGROPECUÁRIA E À AGROINDÚSTRIA, 4., 2003, Porto Seguro. Anais... Lavras: Sociedade Brasileira de Informática Aplicada à Agropecuária e à Agroindústria, 2003. 1 CD-ROM.

MARQUES, A.B. Sistema DGPS Invertido. 2000. 80 f. Dissertação (Mestrado em Sistemas e Computação) - Instituto Militar de Engenharia, Rio de Janeiro, 2000.

MONICO, J.F.G. Posicionamento pelo NAVSTAR-GPS: descrição, fundamentos e aplicações. São Paulo: Editora UNESP, 2000. 287 p.

MORGAN, M.; ESS, D. The precision-farming guide for agriculturists. Ilinois: John Deere Publishing, 1997. $115 \mathrm{p}$.

UMEZU, C.K.; LIMA, T.C.B.; CAPPELLI, N.L; NUNES, E.F. Equipamento microprocessado para geração de sinal de correção diferencial, em tempo real, para GPS. In: CONGRESSO BRASILEIRO DE ENGENHARIA AGRÍCOLA, 33., 2004, São Pedro. Anais... Jaboticabal: Associação Brasileira de Engenharia Agrícola, 2004. 1 CD-ROM.

UMEZU, C.K.; CAPPELLI, N.L. Sistema de baixo custo para geração de sinal de correção diferencial, em tempo real, para GPS. In: CONGRESSO BRASILEIRO DE ENGENHARIA AGRÍCOLA, 31., 2002, Salvador. Anais... Salvador: Sociedade Brasileira de Engenharia Agrícola, 2002. 1 CD-ROM. 